\author{
Supporting Information
}

\title{
Highly efficient degradation of persistent pollutants with 3D nanocone $\mathrm{TiO}_{2}$ based photoelectrocatalysis
}

Rui Song ${ }^{\dagger, 1}$, Haibo Chi ${ }^{\ddagger, \S, 1}$, Qiuling Ma ${ }^{\dagger}$, Dongfeng $\mathrm{Li}^{\S, \infty}$, Xiaomei Wang ${ }^{\dagger}$, Wensheng $\mathrm{Gao}^{\dagger}$, Hao Wang ${ }^{\dagger}$, Xiuli Wang ${ }^{\S}$, Zelong $\mathrm{Li}^{+*}$ and Can $\mathrm{Li}^{\dagger,+, \S, *}$

†Key Laboratory of advanced catalysis, Gansu Province; State Key Laboratory of Applied Organic Chemistry College of Chemistry and Chemical Engineering Lanzhou University Lanzhou, Gansu 730ooo, China

‡School of Chemical and Materials Science, University of Science and Technology of China, Hefei, Anhui 230026, China

\$State Key Laboratory of Catalysis, Dalian Institute of Chemical Physics, Chinese Academy of Sciences; Dalian National Laboratory for Clean Energy, The Collaborative Innovation Center of Chemistry for Energy Materials (iChEM), Zhongshan Road 457, Dalian 116023, China.

${ }^{\infty}$ University of Chinese Academy of Sciences, Beijing 100049, China.

*E-mail: lizl@|zu.edu.cn; canli@dicp.ac.cn 


\section{Experimental procedure}

Chemicals. Ti mesh (100 mesh, purity $>99 \%)$ was purchased from Metal materials for scientific research and experiment Co., Ltd. Titanium isopropoxide (TTIP) was purchased from Acros Organics. Sodium sulphate $\left(\mathrm{Na}_{2} \mathrm{SO}_{4}\right)$, sodium sulfite $\left(\mathrm{Na}_{2} \mathrm{SO}_{3}\right)$, disodium ethylenediamine tetraacetate $\left(\mathrm{Na}_{2} \mathrm{EDTA}\right)$, acetylacetone (ACAC), 4-Chlorophenol (4-CP), 4-Hydroxy-TEMPO (TEMPOL), 5,5-dimethyl-1-pyrroline N-oxide (DMPO), terephthalic acid (TA) were obtained from Macklin Biochemical Co., Ltd. Sodium hydroxide $(\mathrm{NaOH})$ was purchased from Damao Chemical Reagent Factory. Methanol (MeOH), ethanol (EtOH) and isopropyl alcohol (IPA) were purchased from Sinopharm (China). All chemicals used in the experiments were analytical grade without further purification and the solutions were prepared using ultrapure water $(18.25$ $\mathrm{M} \Omega \cdot \mathrm{cm})$.

\section{Structure characterization of catalysts}

SEM images were taken on Thermo Scientific Apreo S (USA).

XRD patterns were recorded by using Rigaku D/Max-2400 (Japan) equipped with a $\mathrm{Cu} \mathrm{Ka}$ radiation operating in a 2-theta range of $10-90^{\circ}$ at a scan rate of $10^{\circ}$ per minute.

Brunauer-Emmett-Teller (BET) surface area and corresponding textural properties were obtained from $\mathrm{N}_{2}$ adsorption-desorption isotherms using 
BET analyzer (Micromeritics ASAP 2460, USA).

X-ray photoelectron spectra (XPS) measurements were conducted on an ESCALAB250xi spectra with an $\mathrm{Al} \mathrm{K} \alpha \mathrm{X}$-ray radiation source $(\mathrm{hv}=$ $1486.6 \mathrm{eV})$.

The energy dispersive spectroscopy (EDS) mapping images were obtained by JSM-7900F.

Mott-Schottky analysis and EIS were acquired using Princeton electrochemical workstation (PARSTAT MC 1000, USA).

Photoluminescence (PL) spectra of photoelectrodes were recorded using a Fluorescence Spectrofluorometer (Edinburgh Instruments FLS920), with the excitation wavelength of $270 \mathrm{~nm}$. PL spectra of TA reacted with hydroxyl radicals were investigated with the excitation wavelength of 310 nm by using Shimadzu RF-5301 spectrophotometer.

The electron paramagnetic resonance (EPR) spectra were collected on a Bruker ER200DSRC 10/12 with a center field at $3362 \mathrm{G}$ and a sweep width of $120 \mathrm{G}$ at room temperature.

The transient adsorption spectrum (TAS) measurements were carried out using the third harmonic of a Nd:YAG laser (EKSPLA, NT 342B, 355 $\mathrm{nm}, 5 \mathrm{~ns}$ pulse width, $0.9 \mathrm{~Hz}$ ) as the pump source. A liquid light guide transmitted the laser pulse to the sample resulting in an incident pump intensity of ca. $210 \mu \mathrm{J} \mathrm{cm}^{-2}(355 \mathrm{~nm})$. A $100 \mathrm{~W}$ tungsten lamp (Bentham, IL 1) coupled to a monochromator (Zolix, Omni - $\lambda$ 300) was used as the 
probe light. Variation in optical density $(\Delta \mathrm{OD})$ of the sample was calculated by measuring the transmitted light using a $\mathrm{Si}$ photodiode (Hamamatsu) and an amplification system coupled to both an oscilloscope (Tektronix, TDS 2012C) and data acquisition card (National Instruments NI-6221). The data were averaged over 300 laser shots. The in-situ TAS experiments were implemented by three-electrode setup controlled by a $\mathrm{CHI} 760 \mathrm{C}$ potentiostat in $0.1 \mathrm{M} \mathrm{Na}_{2} \mathrm{SO}_{4}$ solution $(\mathrm{pH}=$ 6.2), with the photoanode, $\mathrm{Pt}$, and $\mathrm{Ag} / \mathrm{AgCl}$ as working, counter and reference electrodes, respectively. During TAS measurements, a constant potential was maintained by chronoamperometry.

\section{PEC performance of catalysts}

\section{Determination of dechlorination}

The percentage of dechlorination is defined by following equation:

$$
\text { dechlorination } \%=\left[\mathrm{Cl}^{-}\right] /\left[\mathrm{Cl}^{-}\right]_{0}
$$

where $\left[\mathrm{Cl}^{-}\right]$is the concentration of chloride ions which is measured through ion chromatography, $\left[\mathrm{Cl}^{-}\right]_{0}$ is the theoretical maximum concentration of generated chloride ions which is calculated from the practical concentration of 4-CP.

\section{Evaluation of reaction rate}

The reaction rate was evaluated by a pseudo first-order kinetics model:

$$
\ln \left(\mathrm{C}_{0} / \mathrm{C}_{\mathrm{t}}\right)=\mathrm{kt}
$$


where $\mathrm{C}_{0}$ is the initial pollutant concentration, $\mathrm{C}_{\mathrm{t}}$ is the concentration at a certain time $t$ during the degradation process.

\section{Quenching experiments}

For quenching experiments, we used $\mathrm{MeOH}, \mathrm{Na}_{2}$ EDTA and TEMPOL as quenchers for hydroxyl radical, holes and superoxide radical, respectively. Since the concentration of quenchers has influence on the quenching effect, we added different concentration of quenchers to the degradation system. Figure S7 shows that the degradation efficiencies are decreased with increasing concentration of quenchers. However, high concentration quenchers may react with other reactive species, thus we finally chose the concentration of $5 \mathrm{mM}$ for $\mathrm{Na}_{2}$ EDTA and $0.5 \mathrm{M}$ for $\mathrm{MeOH}$, respectively. Besides, since high concentration of TEMPOL has color, which may have negative impact on quenching experiment, we used the concentration of $0.1 \mathrm{mM}$ for TEMPOL.

\section{TAS experiments}

Due to the weak TAS signal of catalysts based on Ti mesh, we used the same methods to prepare catalysts on fluorine-doped tin oxide (FTO) to conduct the TAS analysis. We first made sure that the PEC performance did not change after fabricating on FTO. We tested all the samples in 0.1 $\mathrm{M} \mathrm{Na}_{2} \mathrm{SO}_{4}$ solution under $400 \mathrm{~nm}$ laser light (Fig S21a).

\section{Injection experiments}

Since the water splitting photocurrent of photoelectrodes can be defined 
as:

$$
\mathrm{J}_{\text {photocurrent }}=\mathrm{J}_{\text {abs }} \times \mathrm{P}_{\text {sep }} \times \mathrm{P}_{\text {inj }}
$$

where $\mathrm{J}_{\mathrm{abs}}$ is the rate of photon absorption expressed as a current density, $\mathrm{P}_{\text {sep }}$ is the charge separation yield of the photogenerated carriers, $\mathrm{P}_{\mathrm{inj}}$ is the charge injection yield of electrolyte.

When the holes scavenger $\mathrm{Na}_{2} \mathrm{SO}_{3}$ is present, the photocurrent measured with $\mathrm{Na}_{2} \mathrm{SO}_{3}$ is a product of Jabs and $\mathrm{P}_{\text {sep }}$ only:

$$
\mathrm{J}_{\text {parotocurrent }}^{\mathrm{NaSO}}=\mathrm{J}_{\mathrm{abs}} \times \mathrm{P}_{\text {sep }}
$$

This equation is based on the assumption that the charge injection efficiency is $100 \%$ for $\mathrm{Na}_{2} \mathrm{SO}_{3}$. Since the Psep and Jabs is the same for one catalyst illuminated by same light source, we can obtain the charge injection efficiency by dividing $\mathrm{J}_{\text {photocurrent }}$ by $\mathrm{J}^{\mathrm{Na2SO} 3}{ }_{\text {photocurrent. After }}$ optimizing the concentration of $\mathrm{Na}_{2} \mathrm{SO}_{3}$, we chose $0.4 \mathrm{M} \mathrm{Na}_{2} \mathrm{SO}_{3}$ as holes scavenger with $0.1 \mathrm{M} \mathrm{Na}_{2} \mathrm{SO}_{4}$ to determine $\mathrm{J}^{\mathrm{Na} 2 \mathrm{SO}_{3}}{ }_{\text {photocurrent }}$. To exclude the possible influence of different concentration of $\mathrm{Na}^{+}$, we used $0.5 \mathrm{M}$ $\mathrm{Na}_{2} \mathrm{SO}_{4}$ to determine $\mathrm{J}_{\text {photocurrent }}$.

\section{Determination of the concentration of hydroxyl radicals}

TA was used to determine the concentration of hydroxyl radicals. The initial concentration of TA was $3 \mathrm{mM}$ with $0.01 \mathrm{mM} \mathrm{NaOH}(\mathrm{pH}=11)$. The $\mathrm{NaOH}$ was used to help TA dissolve in the water. The fluorescent product was characterized at $425 \mathrm{~nm}$ when excited with $310 \mathrm{~nm}$ light. Considering negative impact on degradation efficiency from high 
concentration of $\mathrm{OH}^{-}$, the conditions was then set as $3 \mathrm{mM}$ of TA, even if the concentration of $6 \mathrm{mM}$ was more suitable to obtain linear relationship. 


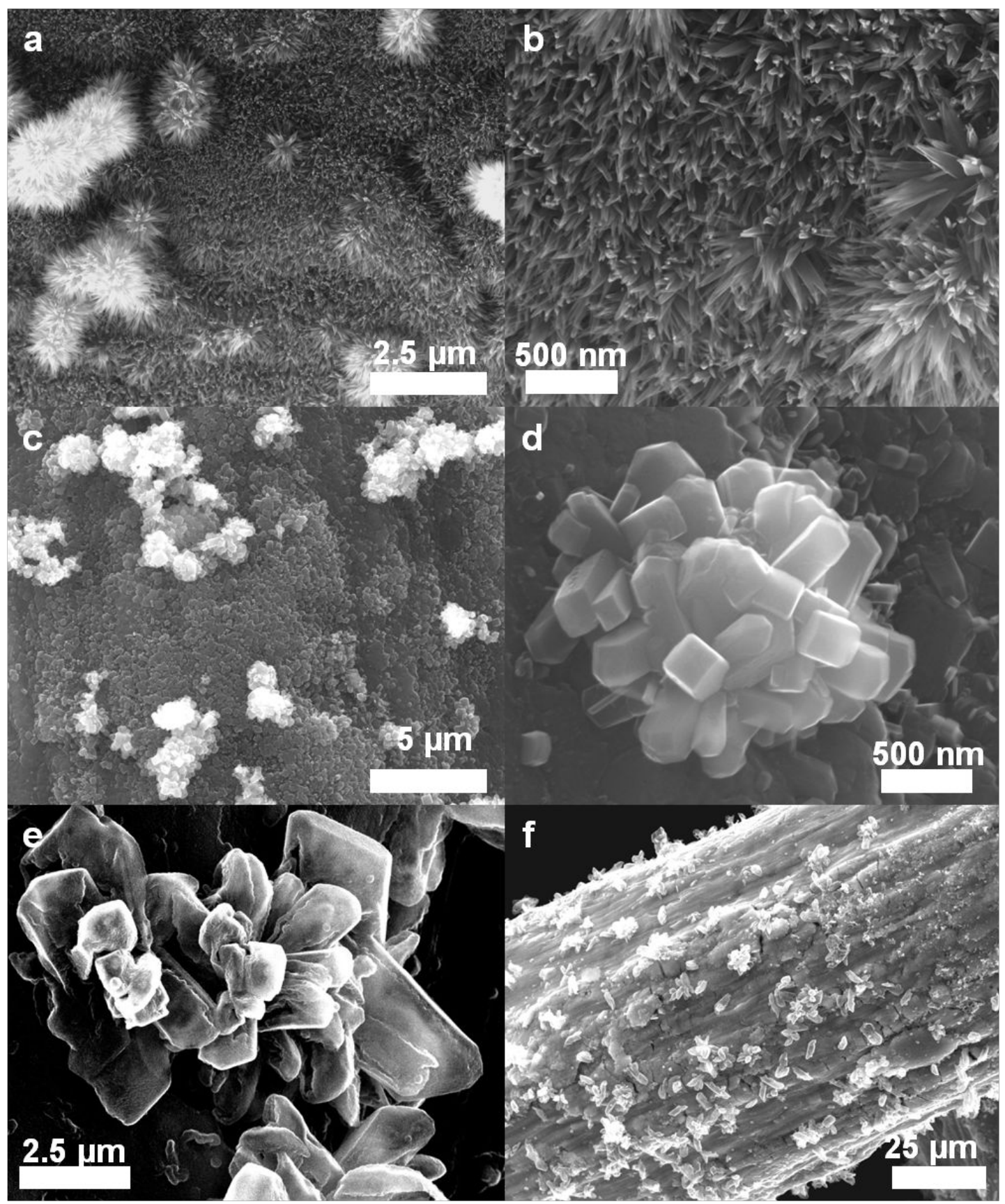

Figure S1: (a) and (b) SEM images of $\mathrm{TiO}_{2} \mathrm{NCs}$. (c) and (d) SEM images of $\mathrm{TiO}_{2}$ NRs. (e) and (f) SEM images of $\mathrm{TiO}_{2} \mathrm{NPs}$. 

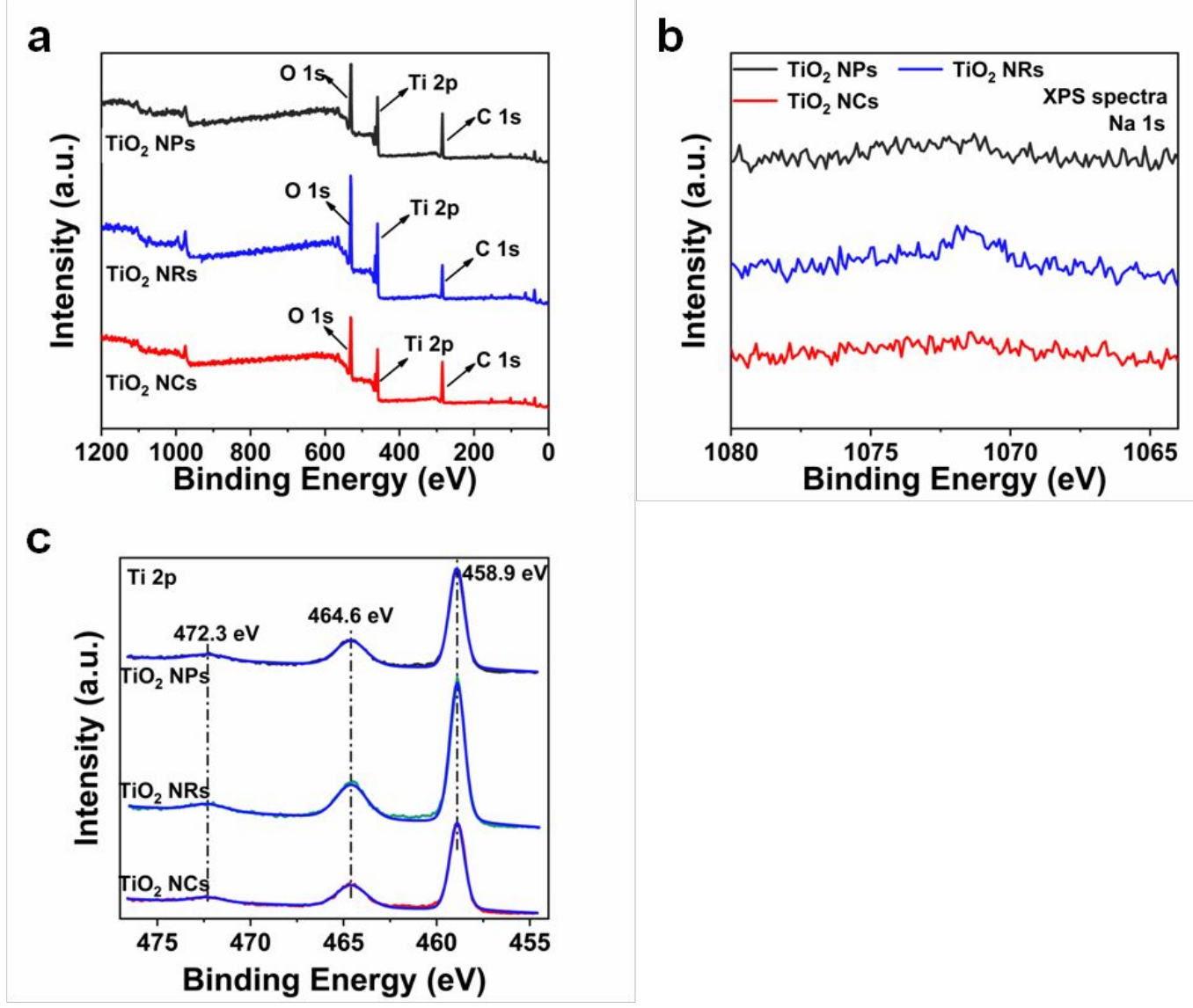

Figure S2. (a) XPS survey spectra of $\mathrm{TiO}_{2}$ catalysts with different morphologies. (b) Na 1s XPS spectra. (c) Ti 2p XPS spectra.

The Ti $2 p$ XPS spectra are identical with Ti $2 p_{3 / 2}$ and $2 p_{1 / 2}$ peaks centered at binding energies of $458.9 \mathrm{eV}$ and $464.4 \mathrm{eV}$. Their satellite peaks are centered at $472.3 \mathrm{eV}$. All the peaks are the typical characteristic $\mathrm{Ti}^{4+}$ binding energies ${ }^{1,2}$. 


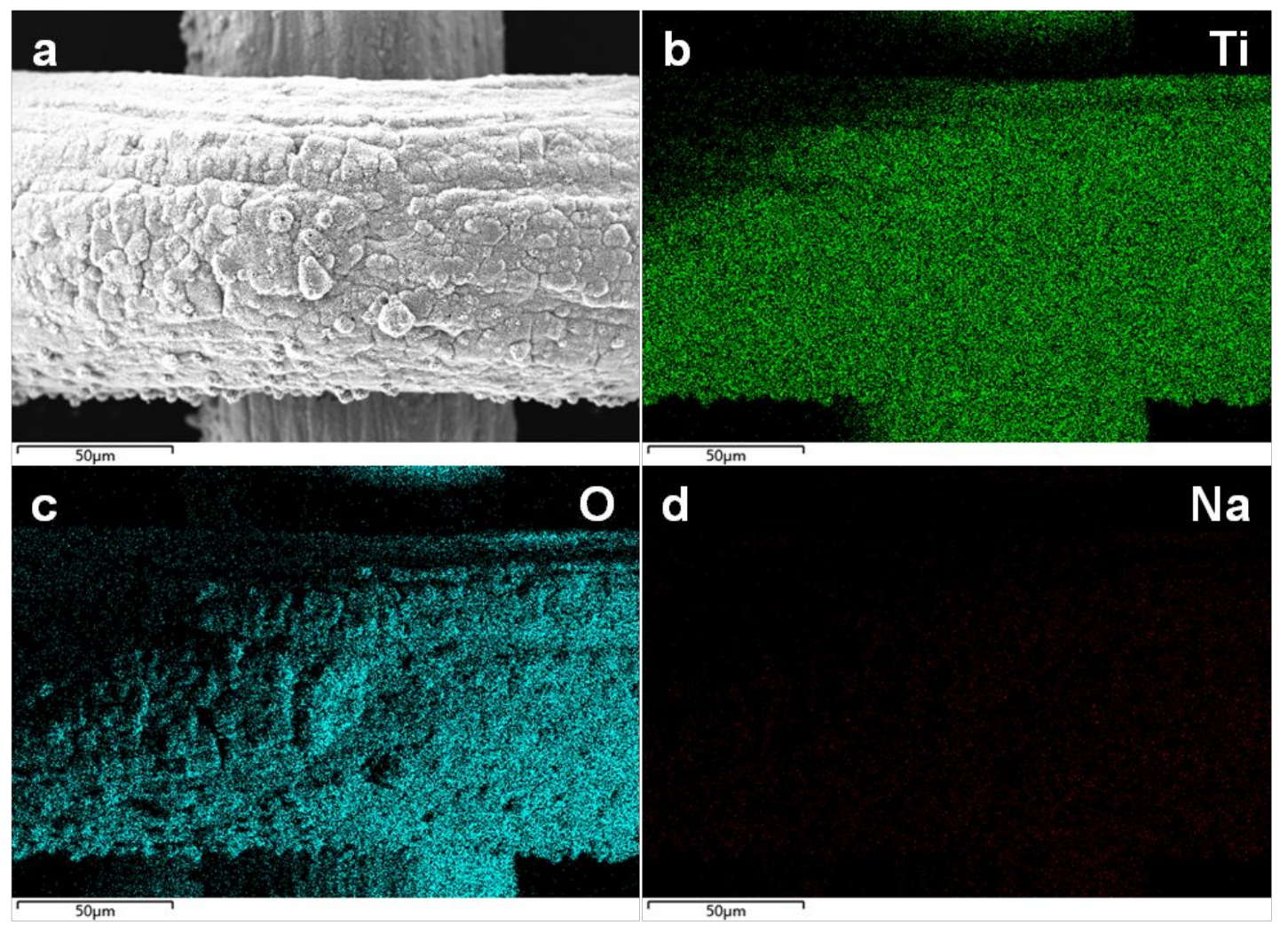

Figure S3. (a) SEM images of $\mathrm{TiO}_{2} \mathrm{NCs}$. The corresponding EDX mapping of (b) Ti, (c) O and (d) Na. 


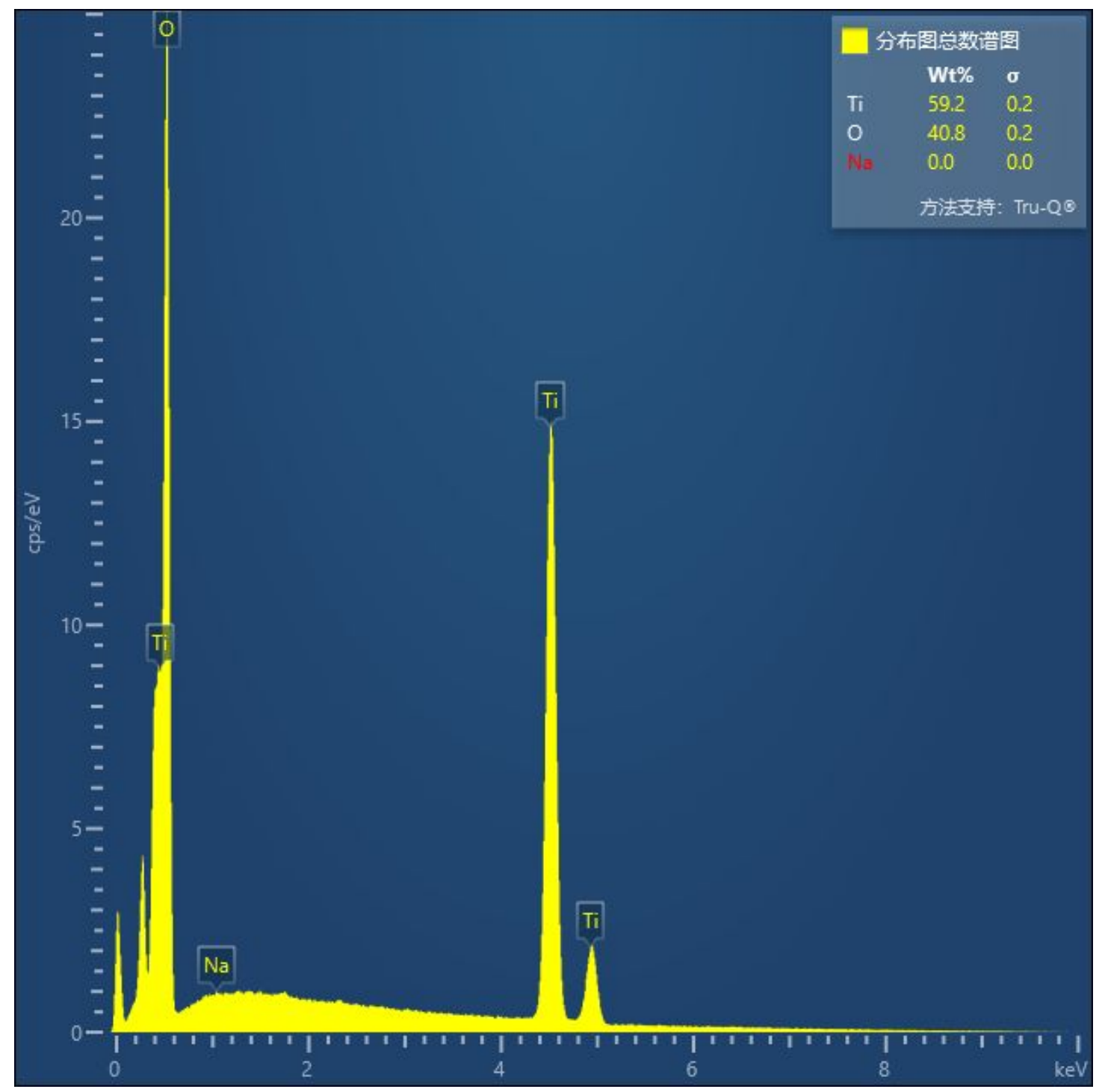

Figure S4. The content of $\mathrm{Ti}, \mathrm{O}$ and $\mathrm{Na}$ elements. 


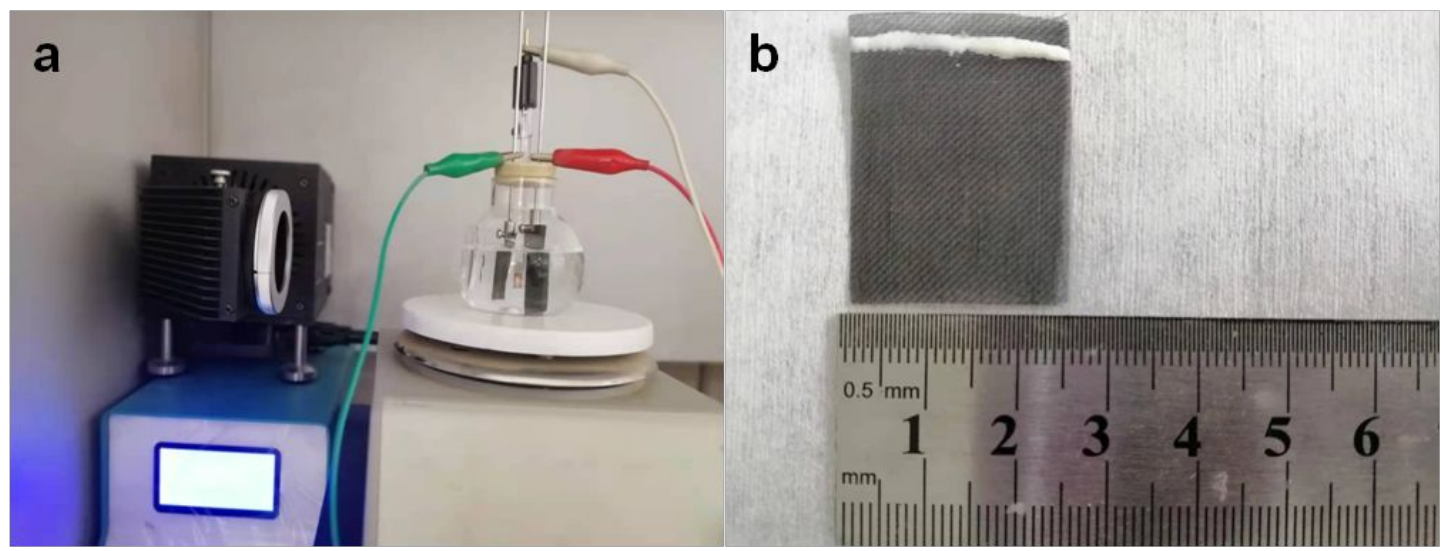

Figure S5: The photograph of (a) experimental set-up and (b) photoanode $\left(\mathrm{TiO}_{2} \mathrm{NCs}\right)$. 

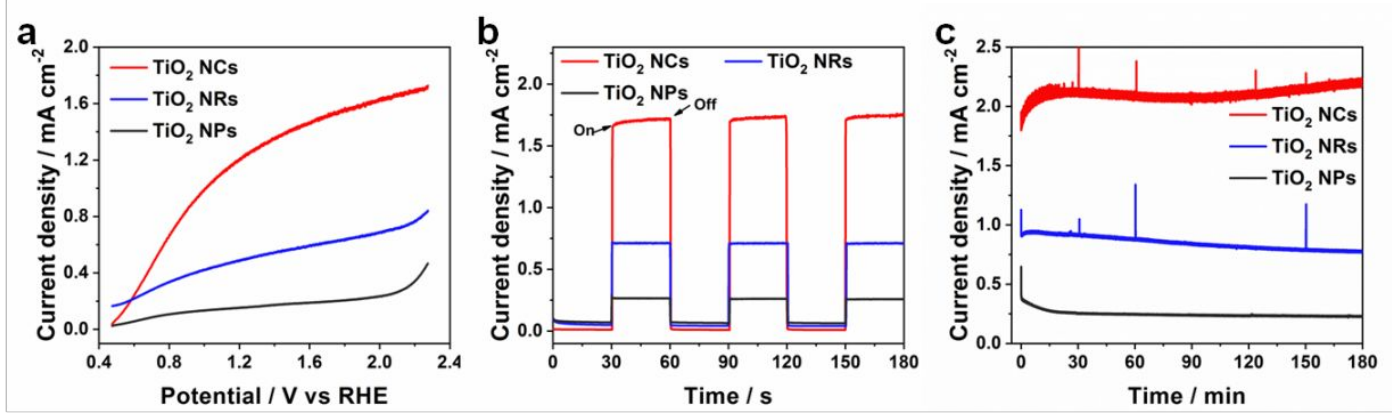

Figure S6. (a) LSV plots of $\mathrm{TiO}_{2}$ catalysts with different structures $(2.5 *$ $3 \mathrm{~cm}^{2}$ ) with $0.1 \mathrm{M} \mathrm{Na}_{2} \mathrm{SO}_{4}$ containing $20 \mathrm{ppm}$ 4-CP (pH=5.67). (b) Transient photocurrent responses of different $\mathrm{TiO}_{2}$ (c) J-t curves of different catalysts during 20 ppm 4-CP degradation. 

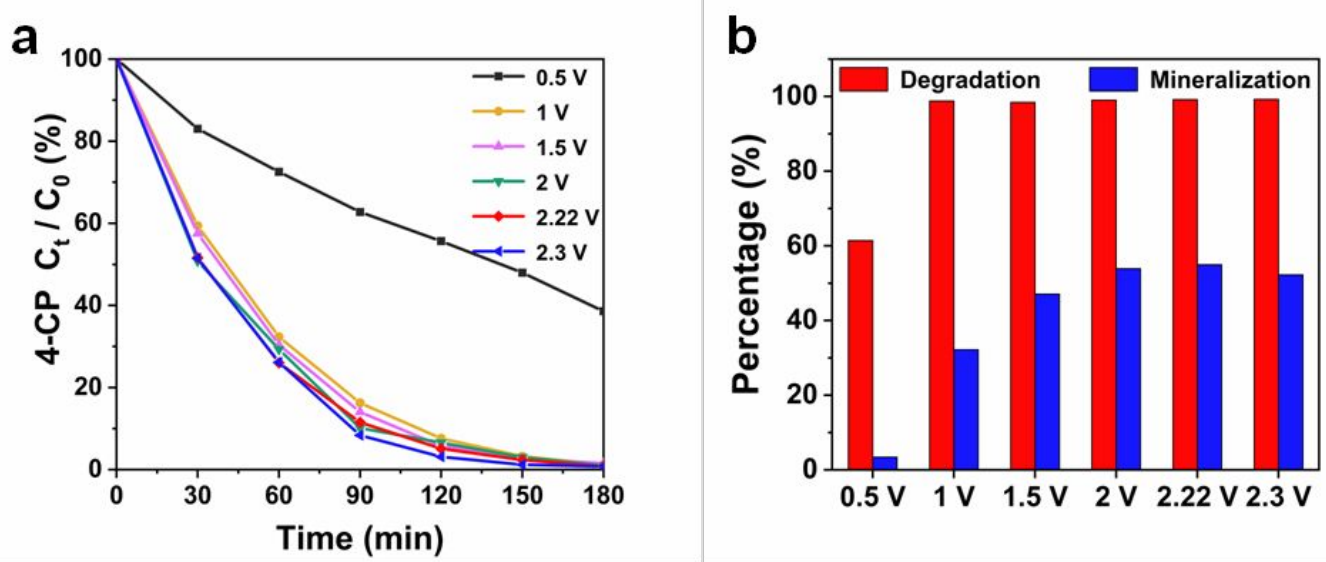

Figure S7. Optimization of bias conditions. 

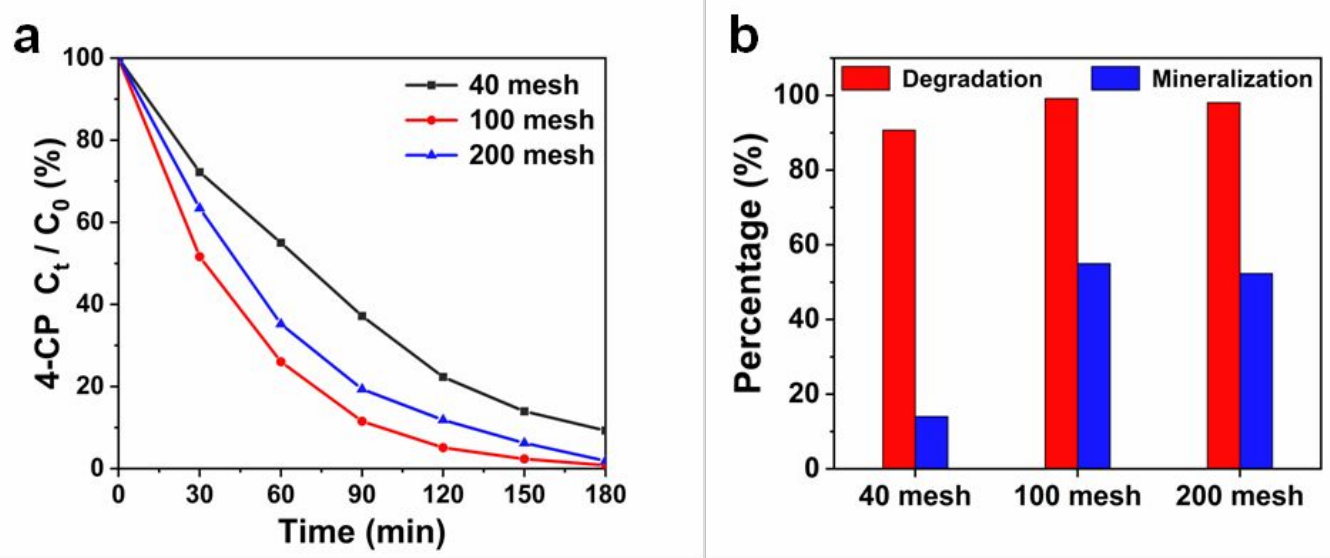

Figure S8. The optimization process of Ti mesh. (a) The degradation of 20 ppm of 4-CP on $\mathrm{TiO}_{2} \mathrm{NCs}$ with different Ti mesh. (b) The efficiencies of degradation and mineralization for $20 \mathrm{ppm}$ of 4-CP degradation on $\mathrm{TiO}_{2} \mathrm{NCs}$ with different Ti mesh. The applied potential is $2.22 \mathrm{~V}$ vs RHE. 

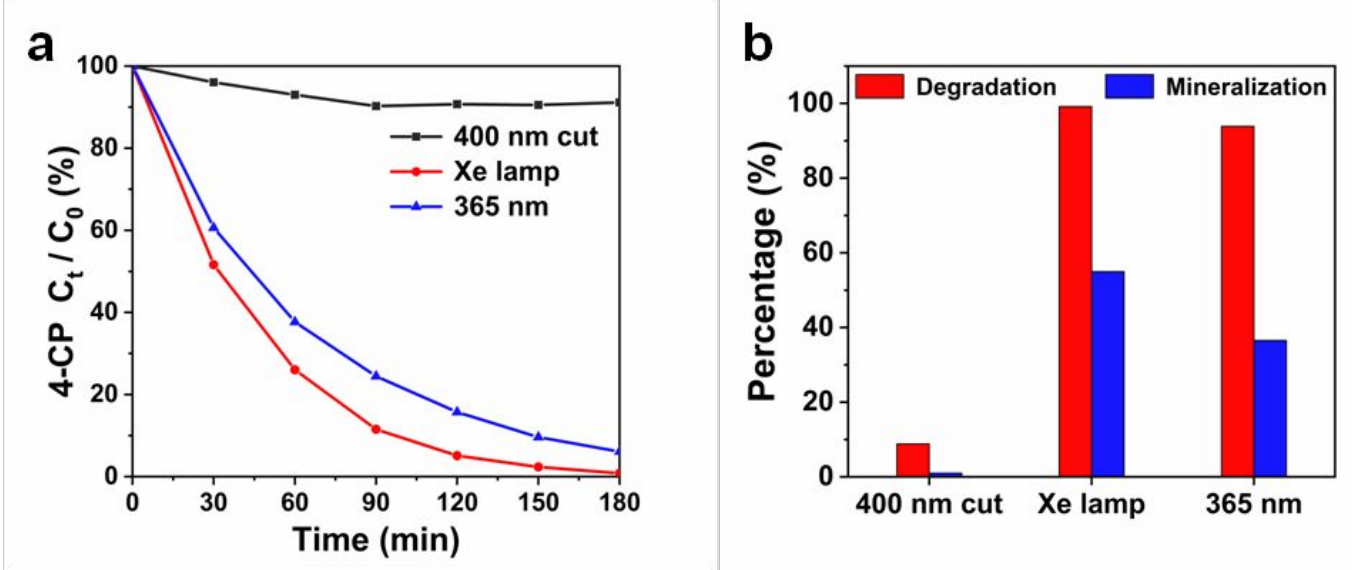

Figure S9. (a) Degradation of $20 \mathrm{ppm}$ of $4-\mathrm{CP}$ on $\mathrm{TiO}_{2} \mathrm{NCs}$ at $2.22 \mathrm{~V}$ vs

RHE under different light sources. (b) Degradation and mineralization efficiencies of degradation of $20 \mathrm{ppm}$ of 4-CP under different light sources. 

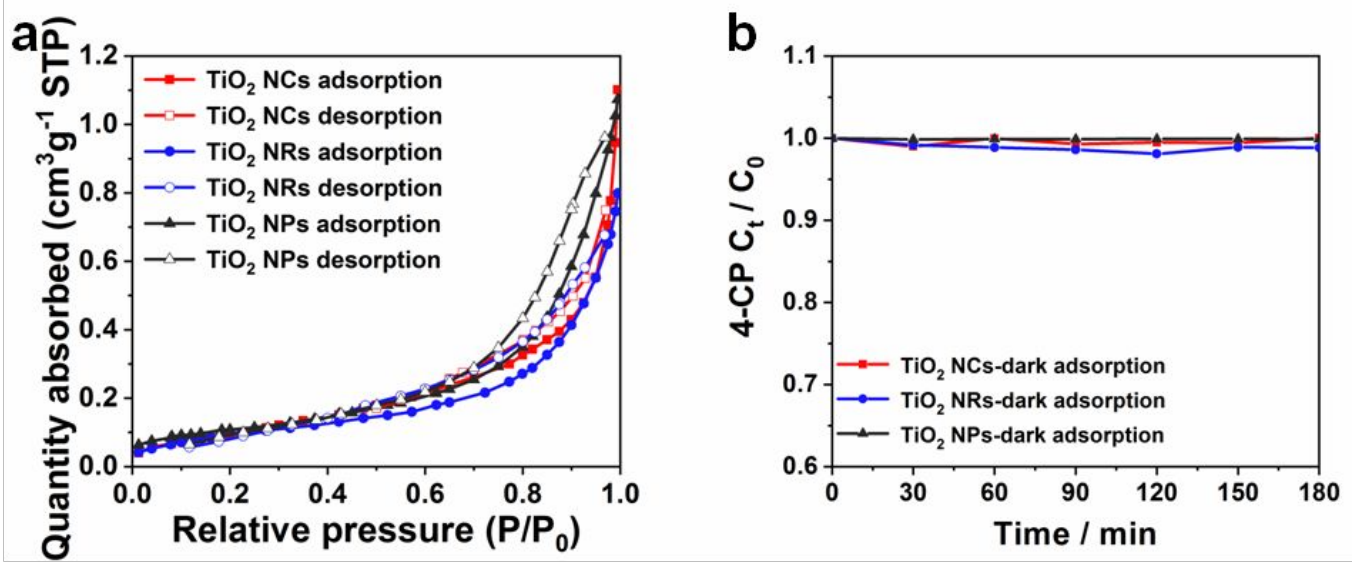

Figure S10: (a) Nitrogen absorption-desorption isotherms of $\mathrm{TiO}_{2}$

catalysts with different structures. (b) Dark adsorption of 4-CP on $\mathrm{TiO}_{2}$ catalysts. 


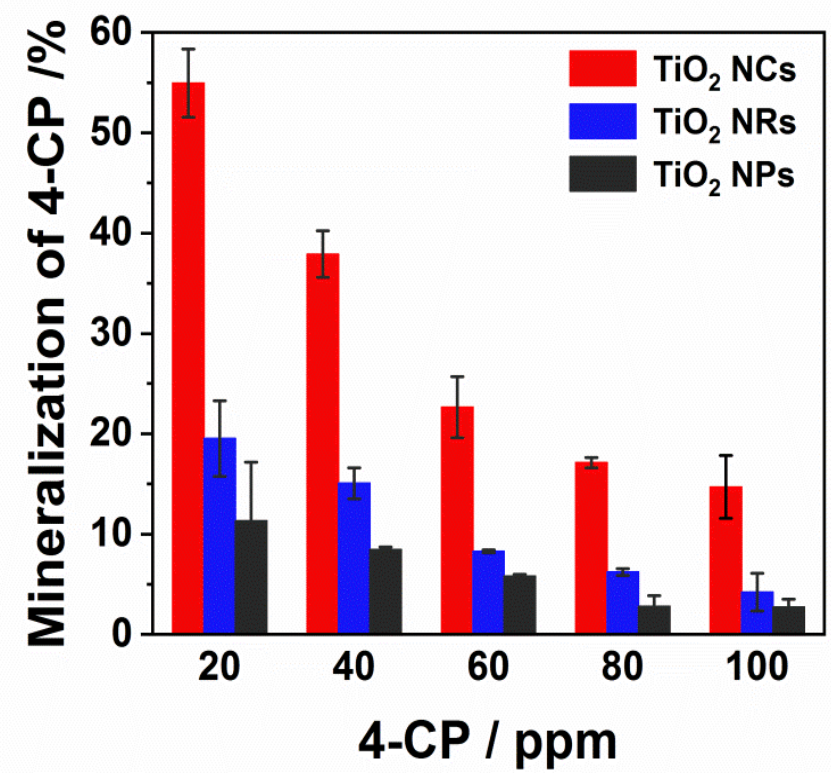

Figure S11. Mineralization efficiencies of different concentration of 4-CP on $\mathrm{TiO}_{2}$ catalysts with different structures. 
a

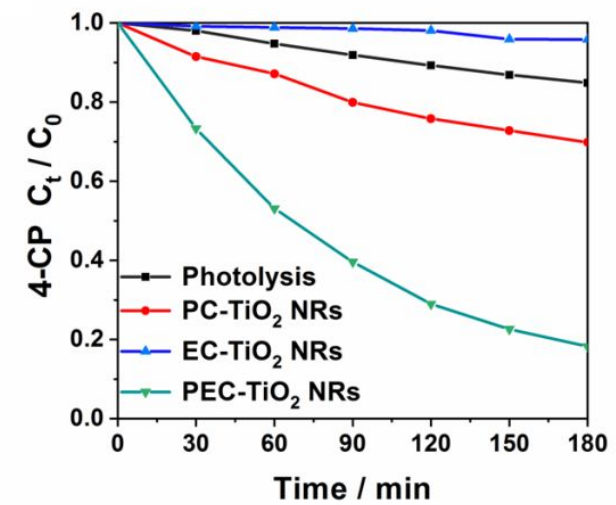

b

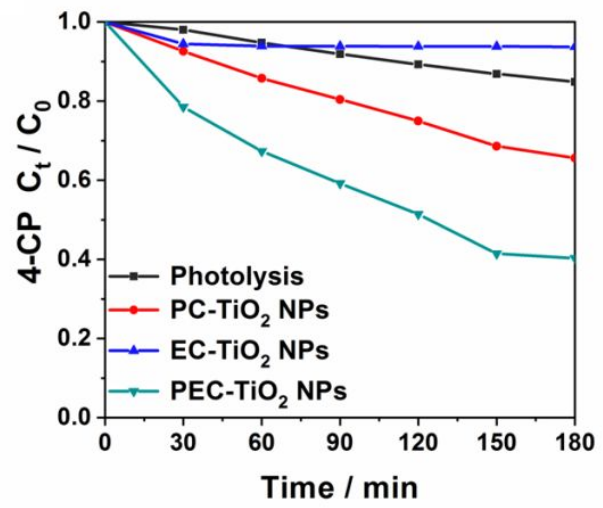

Figure S12: Different degradation process of 4-CP on (a) $\mathrm{TiO}_{2} \mathrm{NRs}$ and (b) $\mathrm{TiO}_{2}$ NPs. 

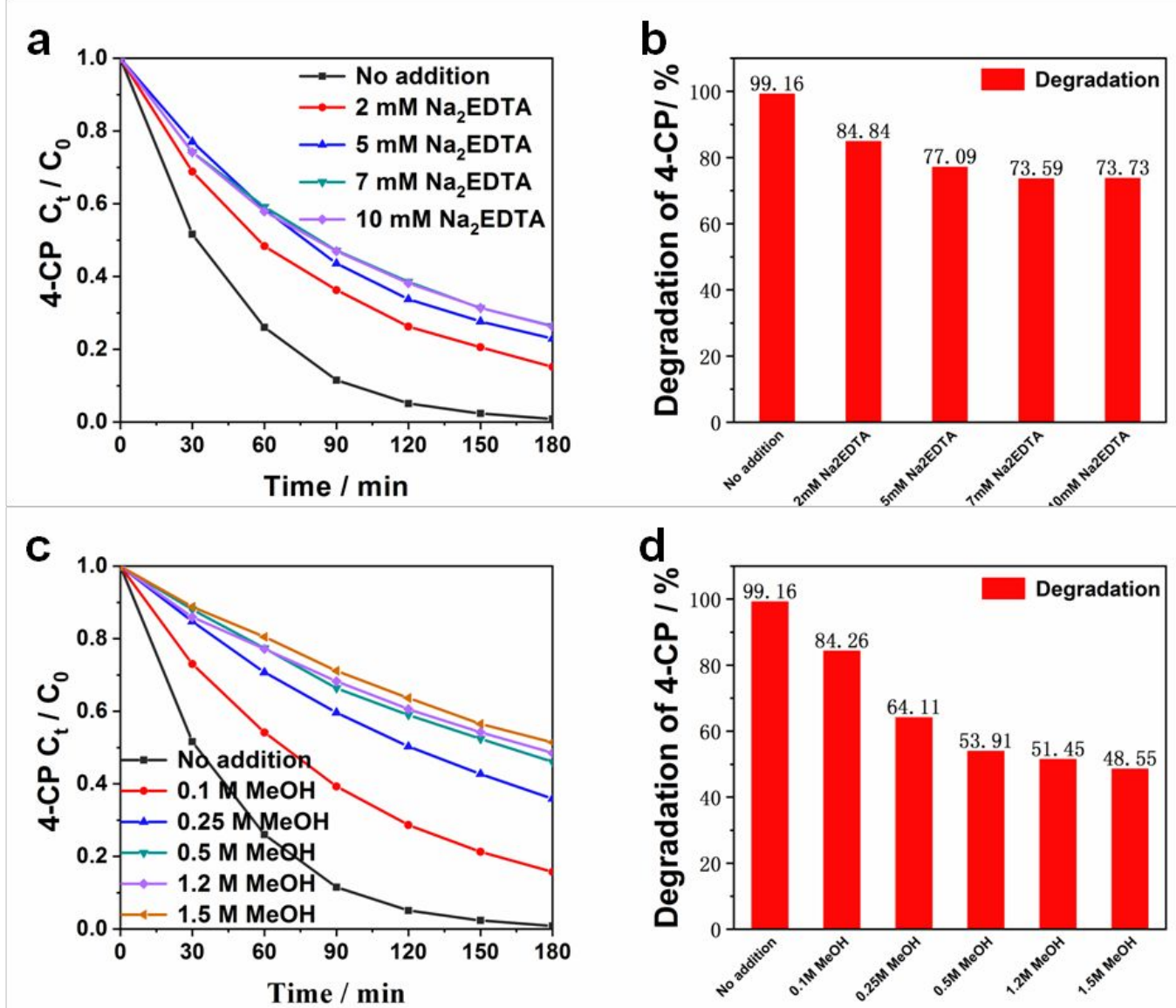

Figure S13: Radical trapping experiments of (a), (b) hydroxyl radicals and (c), (d) holes for different concentration of quenching regents, conducted on $\mathrm{TiO}_{2} \mathrm{NCs}$ catalyst.

Different concentration of quenchers has influence on the quenching experiments. However, high concentration quenchers may react with other reactive species, thus we finally chose the concentration of $5 \mathrm{mM}$ and $0.5 \mathrm{M}$ for $\mathrm{Na}_{2}$ EDTA and $\mathrm{MeOH}$, respectively. Besides, since high concentration of TEMPOL has color, which may have negative impact on quenching experiment, we used the concentration of $0.1 \mathrm{mM}$ for TEMPOL. 


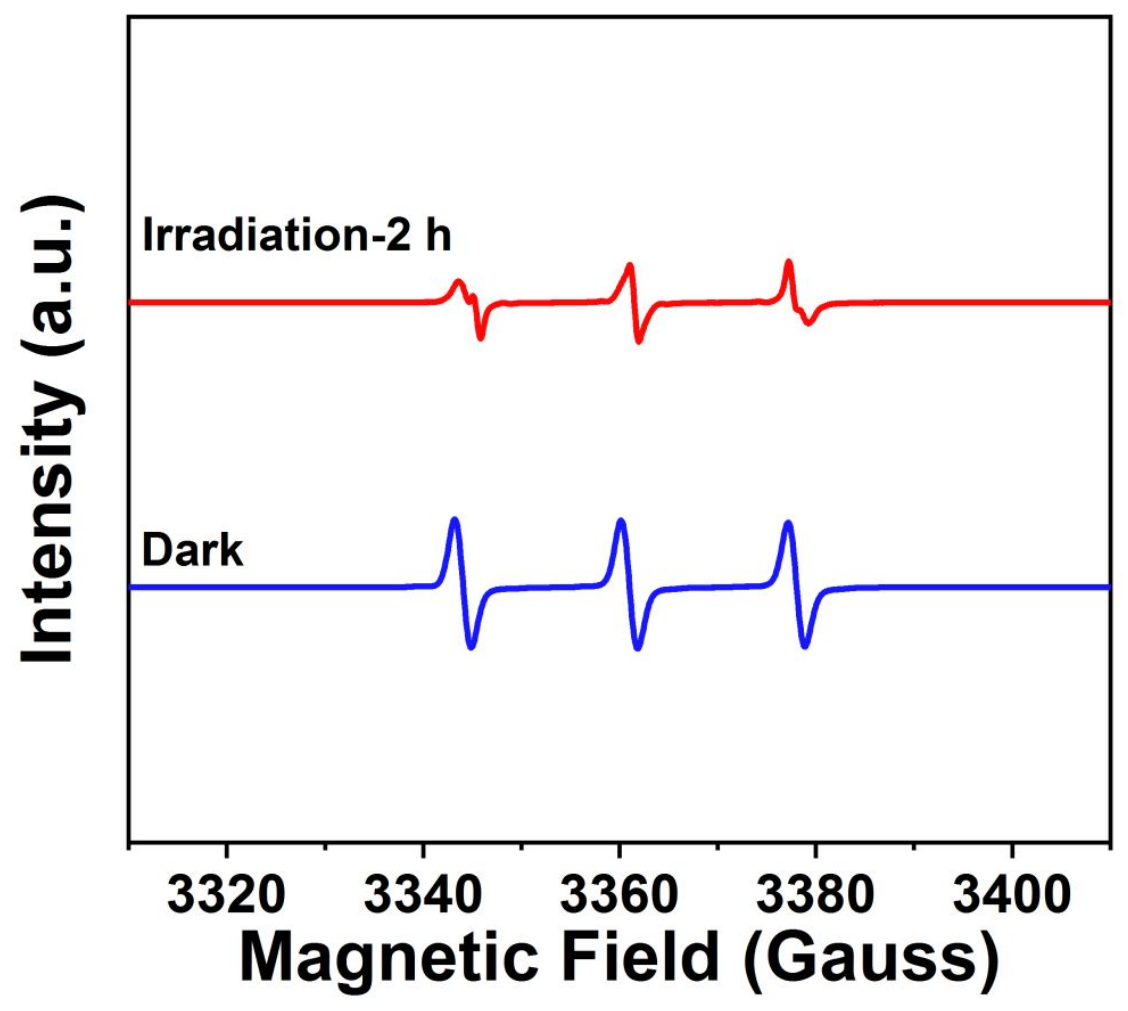

Figure S14: EPR spectra of TEMPOL before and after light illumination. 

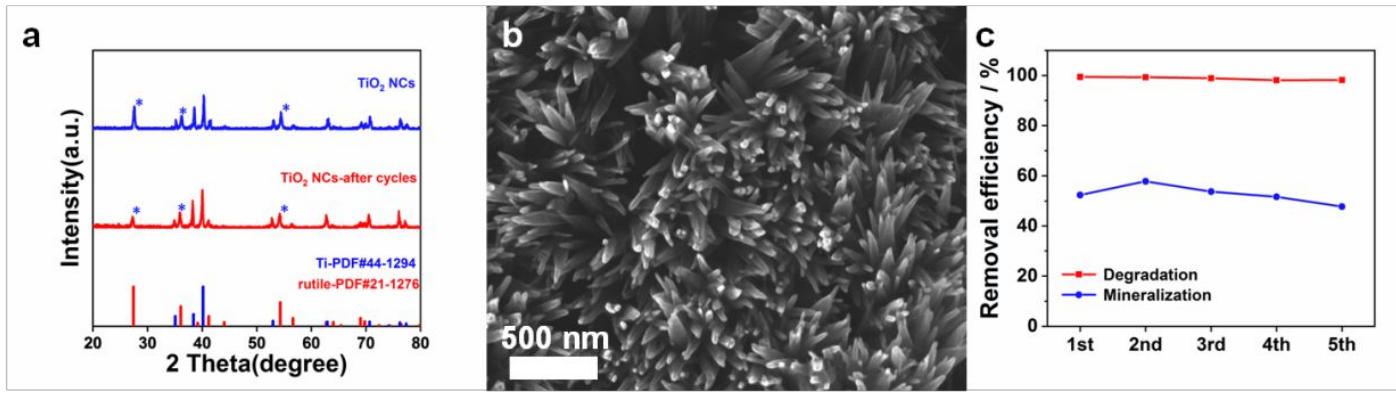

Figure S15: (a) XRD patterns and (b) SEM images of post-TiO $\mathrm{NCs}_{2}$. (c) The efficiency of degradation and mineralization for 5 cycles. 


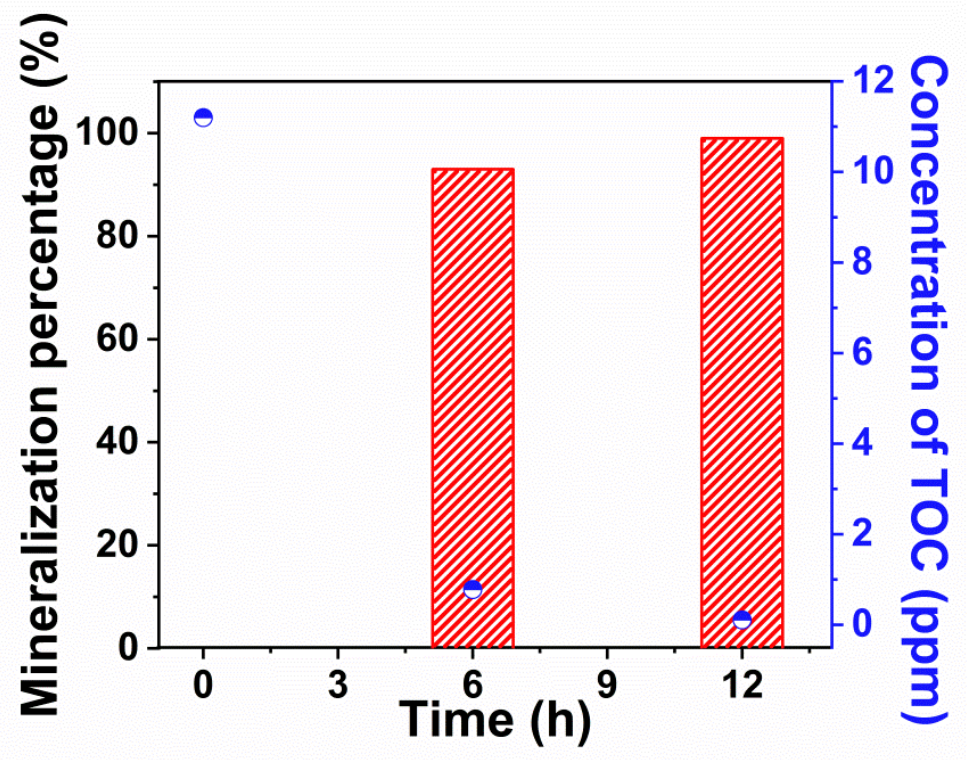

Figure S16. The degree of mineralization and the concentration of TOC after reacting $6 \mathrm{~h}$ and $12 \mathrm{~h}$, respectively. 

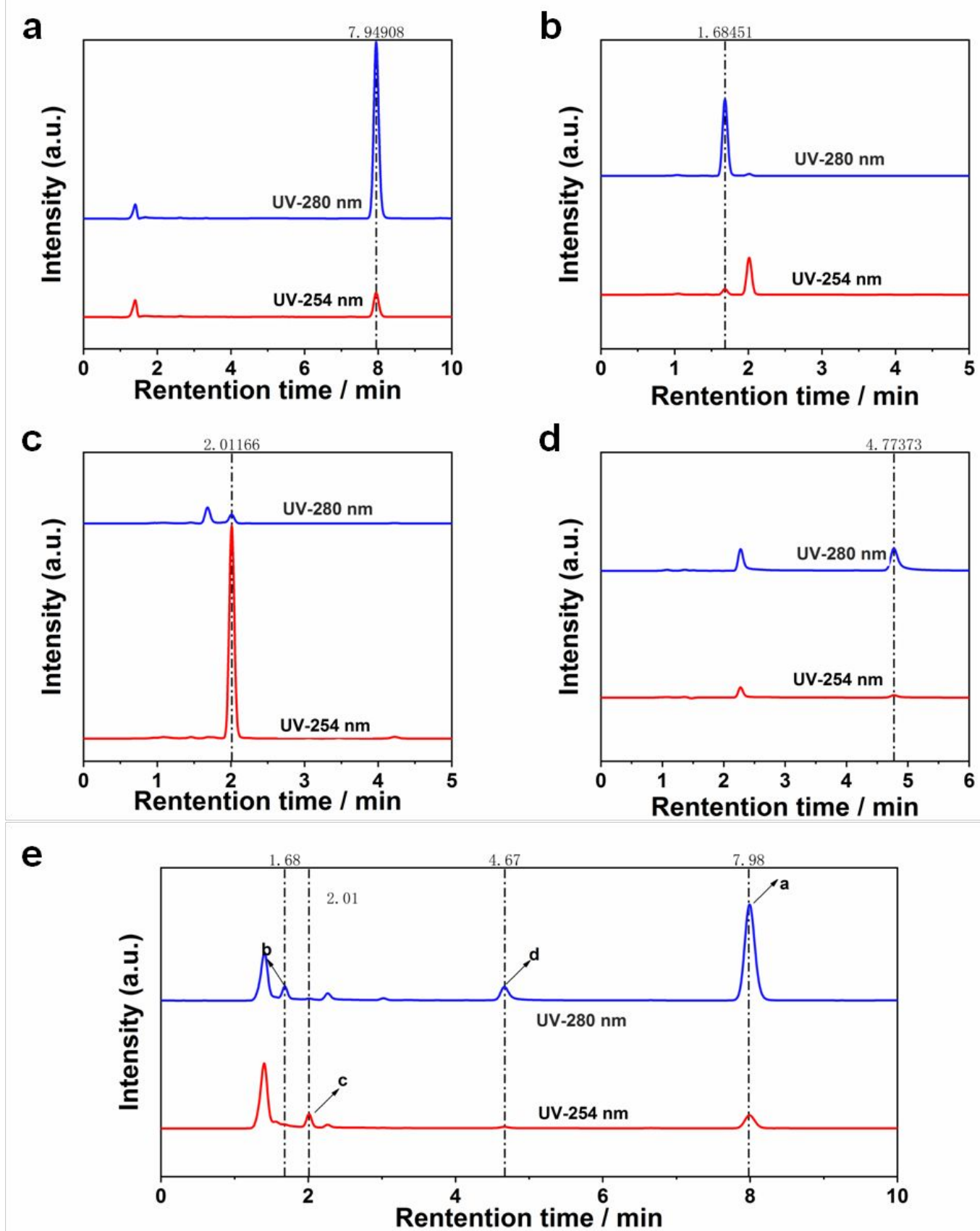

Figure S17: HPLC diagrams of pure sample of (a) 4-CP, (b) HQ, (c) BQ, (d) 4-CC and (e) intermediates of 4-CP degradation process on $\mathrm{TiO}_{2}$ catalysts. Conditions: $\mathrm{MeOH}: \mathrm{H}_{2} \mathrm{O}=50: 50(\mathrm{v} / \mathrm{v}), 1 \mathrm{~mL} / \mathrm{min}$, dual detection wavelength of $280 \mathrm{~nm}$ and $254 \mathrm{~nm}$. 

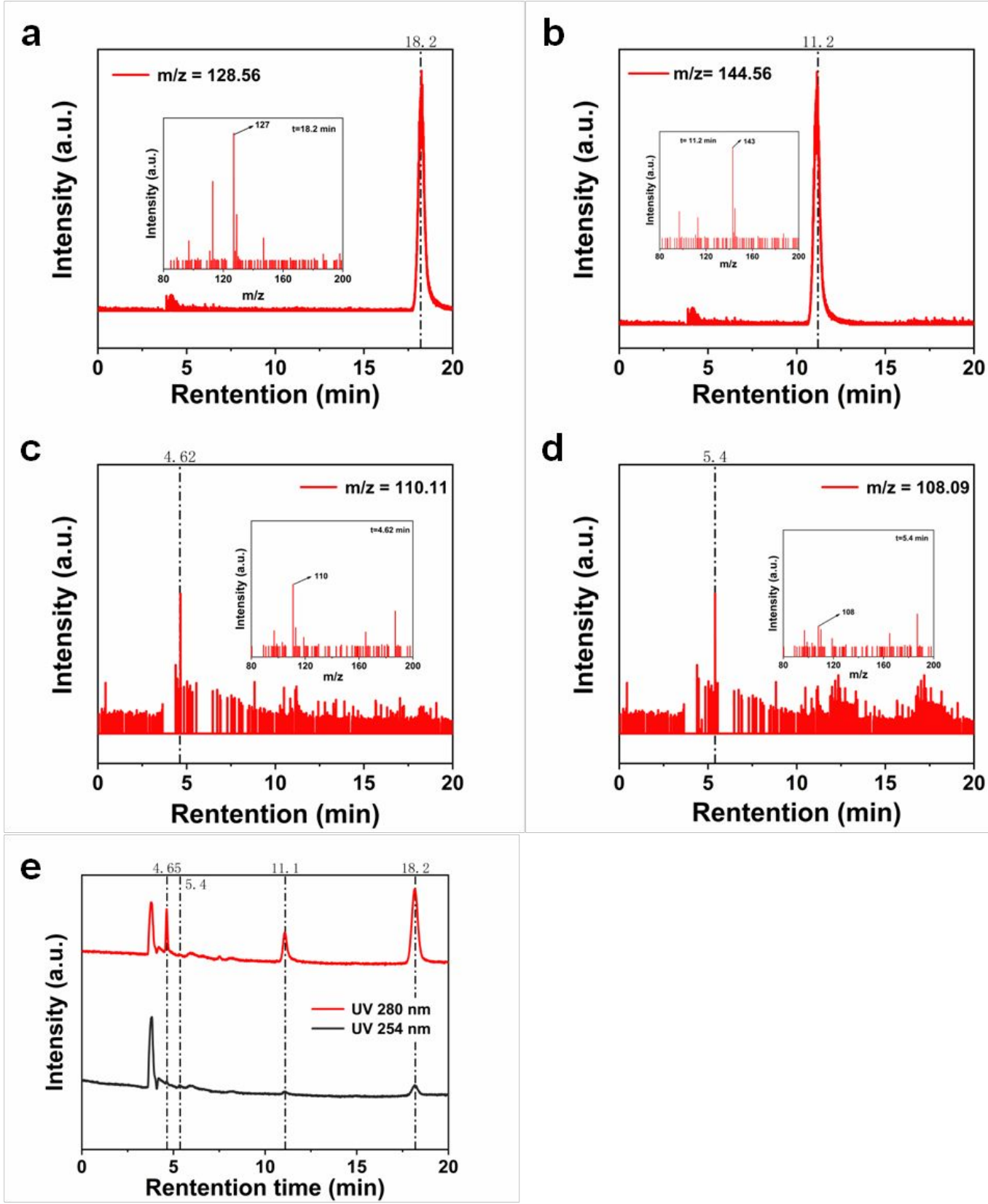

Figure S18: UHPLC-MS diagrams of (a) 4-CP, (b) 4-CC, (c) HQ and (d) BQ on $\mathrm{TiO}_{2}$ catalyst during PEC degradation process. (e) UHPLC diagrams detected with different wavelength. 

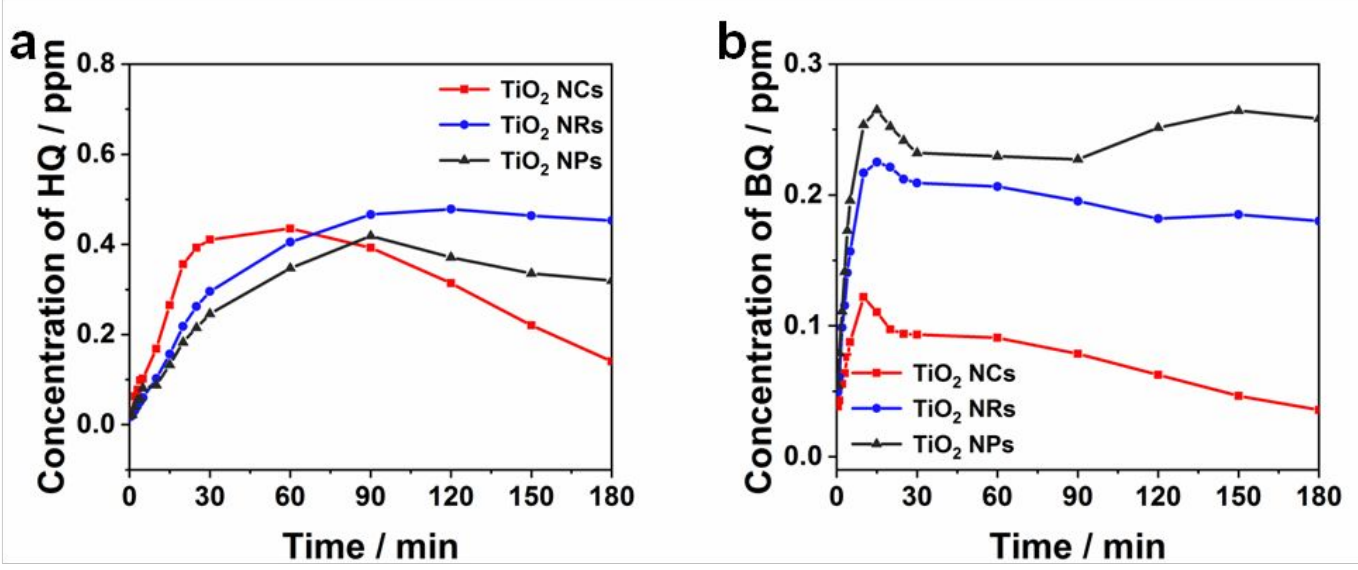

Figure S19: The concentration of generated intermediates of (a) HQ and

(b) $\mathrm{BQ}$ on $\mathrm{TiO}_{2}$ catalysts with different structures during 4-CP

degradation process. The initial concentration of $4-\mathrm{CP}$ is $20 \mathrm{ppm}$. 


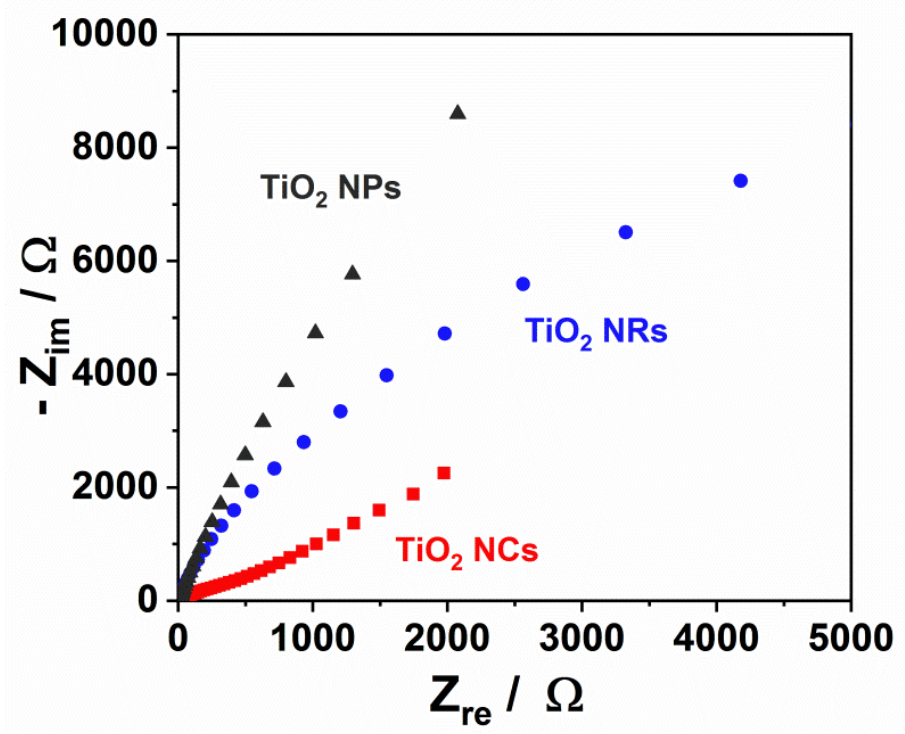

Figure S20: EIS plots of $\mathrm{TiO}_{2}$ catalysts with different structures under dark conditions.

Since the severe OER occurred at $2.22 \mathrm{~V}_{\mathrm{RHE}}$ makes lots of bubbles on the electrodes resulting to incomplete semicircle under light illumination, we choose $0.75 \mathrm{~V}_{\mathrm{RHE}}\left(0.1 \mathrm{~V}_{\mathrm{SCE}}\right)$ to conduct the EIS tests. 

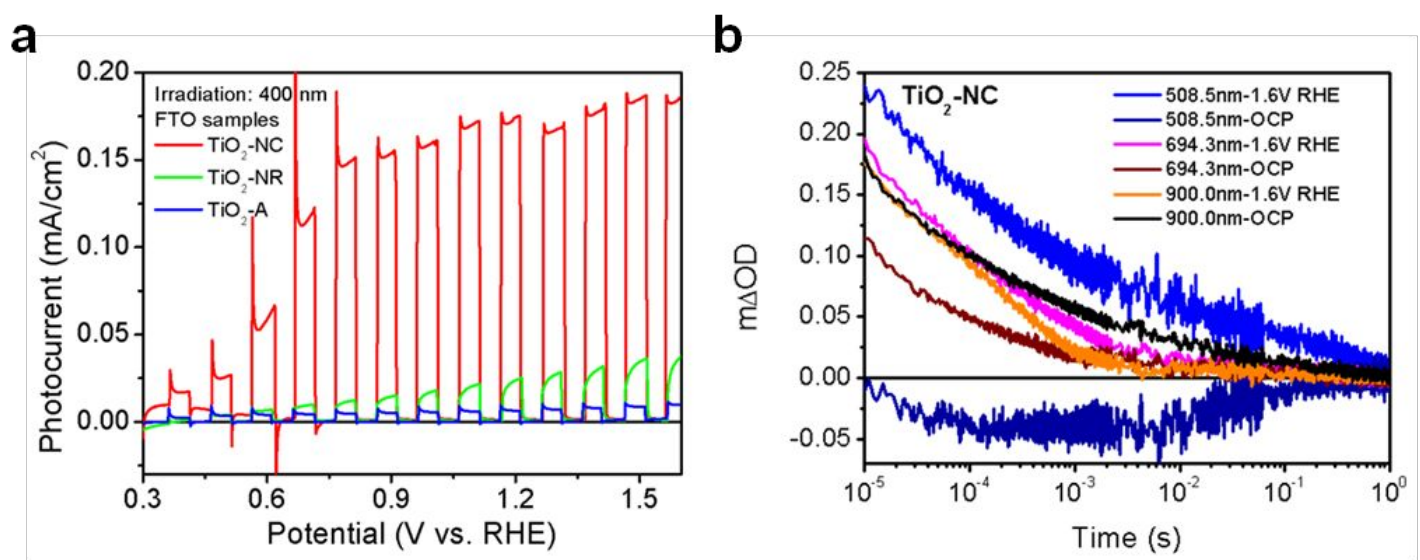

Figure S21: (a) Photocurrent densities of different catalysts prepared on FTO with $0.1 \mathrm{M} \mathrm{Na}_{2} \mathrm{SO}_{4}$. (b) TAS spectra of $\mathrm{TiO}_{2}$ nanocone obtained at different wavelengths.

The PEC performance of $\mathrm{TiO}_{2}$ catalysts fabricated on FTO did not change. 


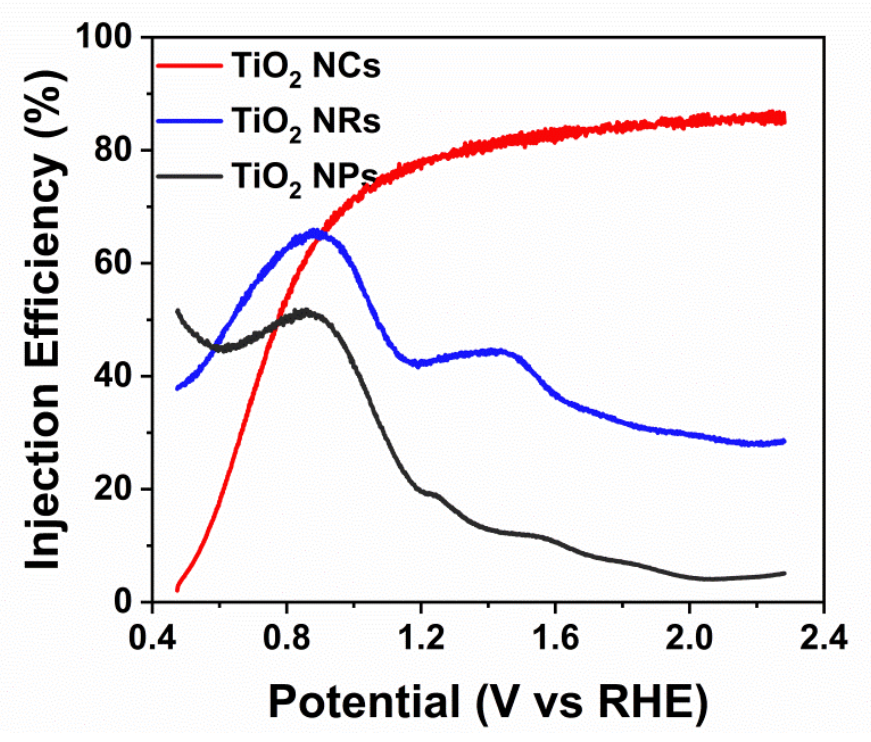

Figure S22. Injection efficiencies of $\mathrm{TiO} 2$ catalysts with different structure. 
a

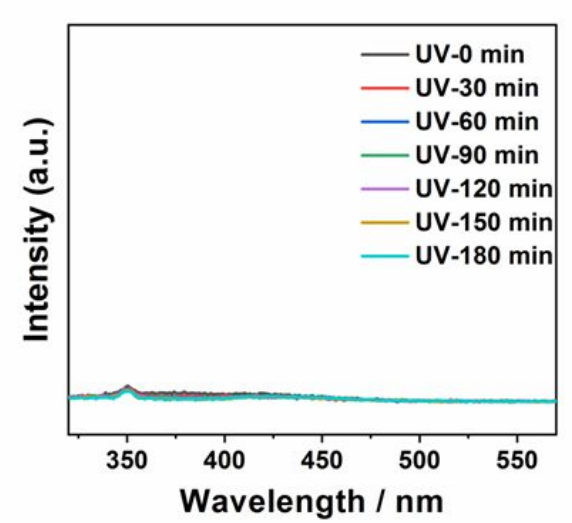

C

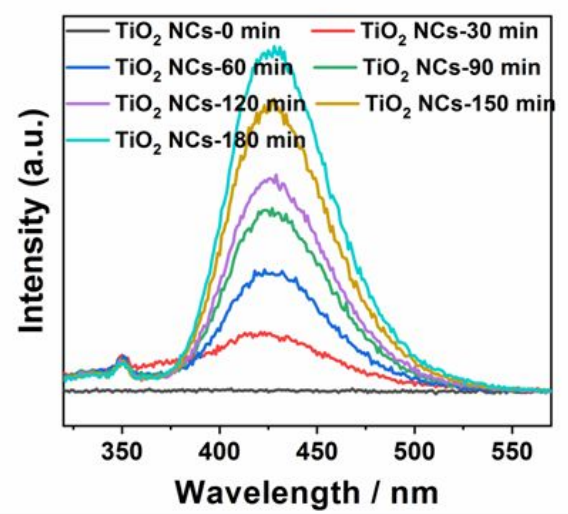

b

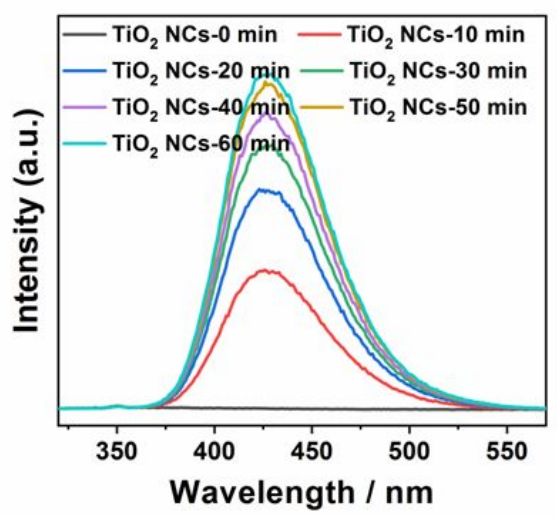

d

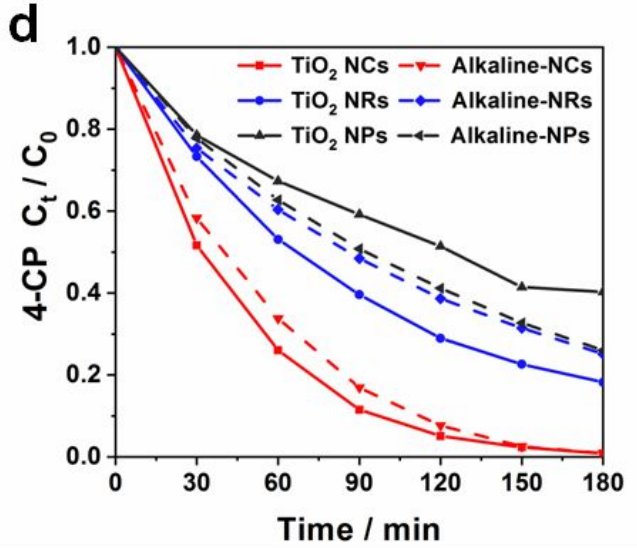

Figure S23: (a) The PL intensity of TAOH without catalysts under light illumination. The PL intensity of $\mathrm{TAOH}$ on $\mathrm{TiO}_{2} \mathrm{NCs}$ when (b) $[\mathrm{TA}]=3$ $\mathrm{mM},[\mathrm{NaOH}]=0.01 \mathrm{mM}$, (c) $[\mathrm{TA}]=6 \mathrm{mM},[\mathrm{NaOH}]=0.02 \mathrm{mM}$. (d) The degradation efficiency of $\mathrm{TiO}_{2}$ catalysts under alkaline conditions $(\mathrm{pH}=$ 11) and experimental conditions.

There is no PL signal when the catalysts are not used, indicating the hydroxyl radicals is generated by catalysts. The increase of PL intensity is not in a constant rate. When the concentration of TA increased to $6 \mathrm{mM}$, PL intensity increased in a constant, demonstrating $3 \mathrm{mM}$ TA was not enough for $180 \mathrm{~min}$. Considering the negative effect of high $\mathrm{pH}$, the concentration was set as $3 \mathrm{mM}$ of TA. 


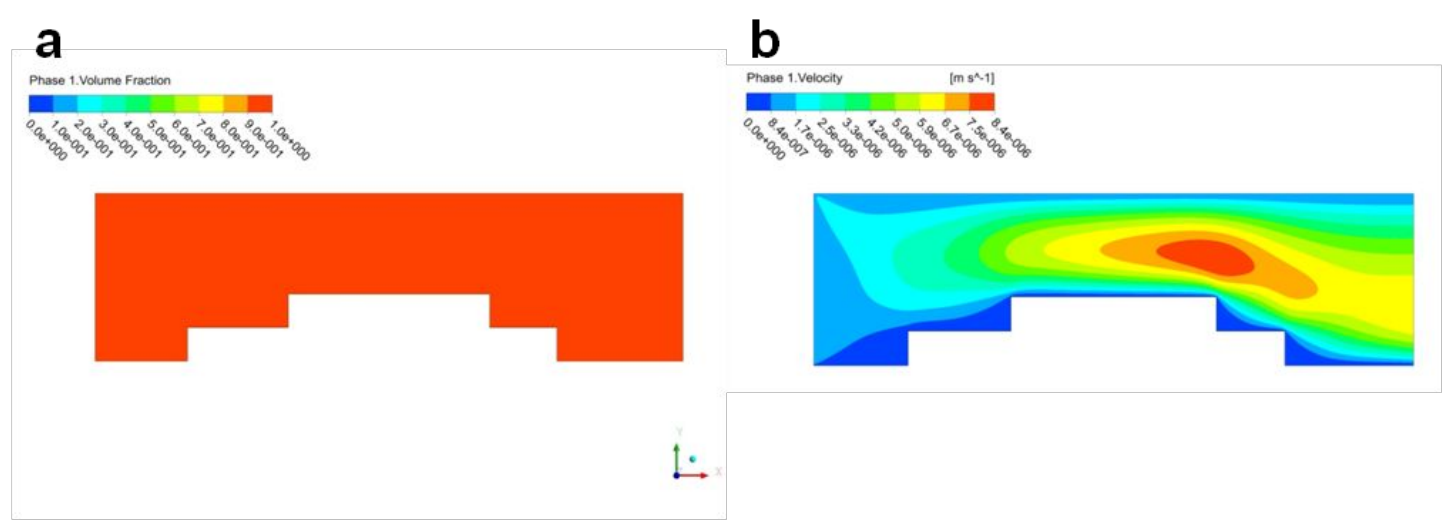

Figure S24: (a) The volume fraction magnitude field of water flow on $\mathrm{TiO}_{2}$ NPs. (b) The velocity magnitude contours of fluent on $\mathrm{TiO}_{2} \mathrm{NPs}$. The CFD model of $\mathrm{TiO}_{2}$ NPs is set three particles to make up, and each one is accordance with the practice size. It leads to a fast flow along the surface of catalyst and circumstance around. 
Table S1: Some data calculated from the experimental results

\begin{tabular}{c|c|c|c}
\hline Sample & $\mathrm{TiO}_{2} \mathrm{NCs}$ & $\mathrm{TiO}_{2} \mathrm{NRs}$ & $\mathrm{TiO}_{2} \mathrm{NPs}$ \\
\hline BET surface area $\left(\mathrm{m}^{2} / \mathrm{g}\right)$ & 0.31 & 0.36 & 0.39 \\
\hline $\mathrm{E}_{\mathrm{FB}} / \mathrm{V}$ vs RHE & 0.204 & 0.164 & -0.016 \\
\hline $\mathrm{L} / \mathrm{nm}$ & 343.23 & 47.66 & 8.86 \\
\hline$\tau_{50 \%} / \mathrm{ms}$ & 0.321 & 0.432 & 1.266 \\
\hline $\mathrm{R}_{\mathrm{ct}} / \Omega$ & 35.9 & 137 & 442.3 \\
\hline
\end{tabular}


Table S2: Summarization of normalized activities for 4-CP degradation.

\begin{tabular}{|c|c|c|c|c|c|c|}
\hline \multirow[t]{2}{*}{ Catalysts } & \multicolumn{2}{|c|}{ Normalized $\mathrm{k}_{\mathrm{obs}}$} & \multirow[t]{2}{*}[\mathrm{C}_{4-\mathrm{CP}}]{} & \multirow[t]{2}{*}{ V } & \multirow[t]{2}{*}{ Light source } & \multirow[t]{2}{*}{ Ref. } \\
\hline & $\mathrm{k} / \mathrm{h}^{-1} \mathrm{~g}^{-1} \mathrm{~m}^{2}$ & $\mathrm{k} / \mathrm{h}^{-1} \mathrm{~cm}^{-2}$ & & & & \\
\hline \multirow[t]{2}{*}{$\mathrm{TiO}_{2} \mathrm{NCs}$} & 3.34 & 0.14 & \multirow[t]{2}{*}{$20 \mathrm{ppm}$} & $1 \mathrm{~V}_{\mathrm{RHE}}$ & $200 \mathrm{~mW} / \mathrm{cm}^{2}$ & \multirow{2}{*}{$\begin{array}{l}\text { This } \\
\text { work }\end{array}$} \\
\hline & 5.05 & 0.22 & & $2.22 \mathrm{~V}_{\mathrm{RHE}}$ & Xe lamp & \\
\hline \multirow[t]{3}{*}{$\mathrm{TiO}_{2}$ TNTs } & $3.52 \times 10^{-3}$ & / & $20 \mathrm{ppm}$ & $0.6 \mathrm{~V}_{\mathrm{SCE}}$ & $200 \mathrm{~W} \mathrm{Hg}$ & \multirow[t]{3}{*}{3} \\
\hline & & & & & lamp 2.5 & \\
\hline & & & & & $\mathrm{mW} / \mathrm{cm}^{2}$ & \\
\hline $\mathrm{TiO}_{2}$ TNTs & / & 0.08 & $100 \mu \mathrm{M}(\sim$ & \multirow[t]{2}{*}{$1.6 \mathrm{~V}_{\mathrm{RHE}}$} & $300 \mathrm{~W}$ Xe lamp & \multirow[t]{2}{*}{4} \\
\hline $\begin{array}{c}\text { Blue-TiO }_{2} \\
\text { TNTs }\end{array}$ & l & 0.4 & 12 ppm) & & $1 \mathrm{~W} / \mathrm{cm}^{2}$ & \\
\hline $\begin{array}{c}\mathrm{N}-\mathrm{TiO}_{2} \\
\text { powder } \\
\text { anode }\end{array}$ & / & 0.0074 & $192 \mu \mathrm{M}$ & $0.27 \mathrm{~V}_{\mathrm{RHE}}$ & $\begin{array}{l}150 \mathrm{~W} \text { halogen } \\
\text { cold lamp }\end{array}$ & 5 \\
\hline P25 anode & 0.0025 & 0.056 & $124 \mu \mathrm{M}$ & $0.6 \mathrm{~V}_{\mathrm{SCE}}$ & $250 \mathrm{~W}$ Xe lamp & 6 \\
\hline $\mathrm{TiO}_{2}$ TNTs & / & 0.032 & $10 \mu \mathrm{M}$ & $1 \mathrm{~V}_{\mathrm{Ag} / \mathrm{AgCl}}$ & Three 0.28 & 7 \\
\hline \multirow{3}{*}{$\begin{array}{c}\mathrm{TiO}_{2} \mathrm{TNTs} \\
+ \text { PDS }\end{array}$} & \multirow[t]{3}{*}{ / } & \multirow[t]{3}{*}{0.063} & & & \multirow{3}{*}{\multicolumn{2}{|c|}{$\begin{array}{c}\mathrm{mW} / \mathrm{cm}^{2} \mathrm{UVA} \\
\text { lamp } \\
350-400 \mathrm{~nm}\end{array}$}} \\
\hline & & & & & & \\
\hline & & & & & & \\
\hline \multirow{3}{*}{$\mathrm{WO}_{3-\mathrm{x}}$ film } & \multirow[t]{3}{*}{ / } & \multirow[t]{3}{*}{0.12} & \multirow[t]{3}{*}{$10 \mathrm{ppm}$} & \multirow[t]{3}{*}{$1.2 \mathrm{~V}_{\mathrm{RHE}}$} & $300 \mathrm{~W}$ Xe lamp & \multirow[t]{3}{*}{8} \\
\hline & & & & & $\begin{array}{c}\text { with AM } 1.5 \mathrm{G} \\
\text { filter }\end{array}$ & \\
\hline & & & & & $100 \mathrm{~mW} / \mathrm{cm}^{2}$ & \\
\hline $\mathrm{WO}_{3}$ & / & 0.075 & $50 \mu \mathrm{M}$ & $0.5 \mathrm{~V}_{\mathrm{Ag} / \mathrm{AgCl}}$ & $\begin{array}{c}300 \mathrm{~W} \text { Xe lamp } \\
\text { with filter } \\
(>420 \mathrm{~nm})\end{array}$ & 9 \\
\hline $\mathrm{Fe}_{2} \mathrm{O}_{3} / \mathrm{ZnO}$ & / & 0.024 & $10 \mathrm{ppm}$ & $1 \mathrm{~V}_{\mathrm{RHE}}$ & $\begin{array}{c}300 \mathrm{~W} \text { Xe lamp } \\
\text { with filter } \\
(>420 \mathrm{~nm})\end{array}$ & 10 \\
\hline $\mathrm{Bi}_{2} \mathrm{WO}_{6}$ & / & 0.0048 & $10 \mathrm{ppm}$ & $2 \mathrm{~V}_{\mathrm{RHE}}$ & $\begin{array}{c}150 \mathrm{~mW} / \mathrm{cm}^{2} \\
\text { visible light }\end{array}$ & 11 \\
\hline
\end{tabular}


References:

(1) Chen, X.; Liu, L.; Yu, P. Y.; Mao, S. S. Increasing Solar Absorption for Photocatalysis with Black Hydrogenated Titanium Dioxide Nanocrystals. Science 2011, 331, 746-750.

(2) Wang, G.; Wang, H.; Ling, Y.; Tang, Y.; Yang, X.; Fitzmorris, R. C.; Wang, C.; Zhang, J. Z.; Li, Y. Hydrogen-treated TiO2 nanowire arrays for photoelectrochemical water splitting. Nano Lett. 2011, 11, 3026-3033. (3) Wang, N.; Li, X.; Wang, Y.; Quan, X.; Chen, G. Evaluation of bias potential enhanced photocatalytic degradation of 4-chlorophenol with TiO2 nanotube fabricated by anodic oxidation method. Chem. Eng. J. 2009, 146, 30-35.

(4) Koo, M. S.; Cho, K.; Yoon, J.; Choi, W. Photoelectrochemical Degradation of Organic Compounds Coupled with Molecular Hydrogen Generation Using Electrochromic TiO2 Nanotube Arrays. Environ. Sci. Technol. 2017, 51, 6590-6598.

(5) Zhou, D.; Dong, S.; Shi, J.; Cui, X.; Ki, D.; Torres, C. I.; Rittmann, B. E. Intimate coupling of an $\mathrm{N}$-doped $\mathrm{TiO} 2$ photocatalyst and anode respiring bacteria for enhancing 4-chlorophenol degradation and current generation. Chem. Eng. J. 2017, 317, 882-889.

(6) Vinodgopal, K.; Stafford, U.; Gray, K. A.; Kamat, P. V. Electrochemically Assisted Photocatalysis. 2. The Role of Oxygen and Reaction Intermediates in the Degradation of 4-Chlorophenol on 
Immobilized TiO2 Particulate Films. J. Phys. Chem. 1994, 98, 6797-6803.

(7) Son, A.; Lee, J.; Lee, C.; Cho, K.; Lee, J.; Hong, S. W. Persulfate enhanced photoelectrochemical oxidation of organic pollutants using self-doped TiO2nanotube arrays: Effect of operating parameters and water matrix. Water Res. 2021, 191, 116803.

(8) Liu, X.; Zhou, H.; Pei, S.; Xie, S.; You, S. Oxygen-deficient WO3-x nanoplate array film photoanode for efficient photoelectrocatalytic water decontamination. Chem. Eng. J. 2020, 381, 122740.

(9) Koo, M. S.; Chen, X.; Cho, K.; An, T.; Choi, W. In Situ Photoelectrochemical Chloride Activation Using a WO3 Electrode for Oxidative Treatment with Simultaneous H2 Evolution under Visible Light. Environ. Sci. Technol. 2019, 53, 9926-9936.

(10) Cheng, L.; Liu, L.; Li, R.; Zhang, J. Liquid Phase Deposition of $\alpha-\mathrm{Fe} 2 \mathrm{O} / \mathrm{ZnO}$ Heterojunction Film with Enhanced Visible-Light Photoelectrocatalytic Activity for Pollutant Removal. J. Electrochem. Soc. 2017, 164, H726-H733.

(11) Zhao, X.; Xu, T.; Yao, W.; Zhang, C.; Zhu, Y. Photoelectrocatalytic degradation of 4-chlorophenol at Bi2WO6 nanoflake film electrode under visible light irradiation. Appl. Cata., B: Environ. 2007, 72, 92-97. 